\title{
Wittgenstein on representability and possibility
}

\section{Introduction}

It is a central claim of the Tractatus that a proposition "contains the possibility of the state of affairs it represents" (TLP \$2.203). This essay seeks to understand this claim, and so to understand why "we cannot think anything unlogical" (TLP \$3.03), why "it is impossible to judge a nonsense" (TLP \$5.5422).

According to Wittgenstein's picture theory, elementary judgments or propositions are combinations of names, with each name standing for an object. And what such a proposition represents is that the objects combine in the same way as their names are combined within the representation (TLP \$\$2.13-2.15). In this context, Wittgenstein's stance against thinking something illogical, the stance against nonsense, goes in hand with a view that a name shares a form with the object it names. A name's form or syntactic kind is given by the ways in which it can combine with other names in elementary propositions, the combinatorial roles it can play with other names. Similarly, an atomic fact or possibility consists of objects (TLP \$2.01), and an object's form or ontological kind is given by the ways in which it can participate in such facts, the combinatorial roles it can play with other objects (TLP \$2.0141). If, then, a name's form matches that of its referent, then what a proposition represents, namely that the objects combine in the same way as their names, will be a possibility for those objects. The elementary proposition will represent an atomic fact.

In what follows I shall consider various lines of interpretation of the Tractatus on 'the relation between language and reality', seeking in each case to understand what account is offered, or made available, of the name-object identity of form and the stance against nonsense. First in section 2 I shall consider a number of realist readings ( 3 or 4 , depending on how you count them), readings on which the Tractarian world is theoretically independent of any matter of thought or language. Subsequently in section 3 I shall set out two non-realist readings on which the Tractarian ontology is to be understood only in connection with language. The readings will all be assessed, as said, for the understanding they provide of the impossibility of nonsense, but I don't want to stipulate in advance what kind of understanding it is we are after. Perhaps the stance will appear as a consequence of weaker premises. Or perhaps it will fall out of certain Tractarian conceptions: Wittgenstein's conception of reference, for example, or of fact. It will be deemed unacceptable, however, to suppose that Wittgenstein simply assumes nonsense to be impossible, and similarly unacceptable to suppose that he in effect stipulates the matter. Any claim that the stance against nonsense is implicit within the Tractarian conception of reference, say, will need to unpack other than as a matter of terminology.

\section{Realism and the name-object identity of form}

\subsection{Introduction}

Realist interpretations of the Tractatus understand its metaphysics as theoretically independent of its philosophy of language. The forms, or natures, of Tractarian facts and objects have in themselves nothing to do with representation. This view obviously constrains how one might explain Wittgenstein's harmony between language and reality, a harmony such that a name shares a form with the object it means and a proposition represents a possibility. If the world is ignorant in itself of any matter of language, then nothing worldly can be appealed to in explaining why it matches language. So how else is the match to be explained?

This call for explanation has on occasion been rejected by the realist. Peter Hacker, for example, writes that "[i]t was an unargued assumption of the Tractatus that one cannot think a nonsense" (Hacker 1999 
p132). But if Hacker's claim is what it seems to be, namely that Wittgenstein's book provides no understanding of why nonsense should be impossible, then it amounts to a radical downgrading of the book's interest. If Wittgenstein really has nothing to offer us as this central philosophical and textual juncture, then we should simply move on to another, richer author. But there is an obvious alternative for the realist to this 'brute premise' response. The realist can look to understand the harmony as a consequence, or aspect, of the kind of connections language makes to the world. Language connects to the language-independent world, and the nature of this connection dictates that what is so connected must be in conformity with the world to which it connects.

So what is the connection between language and the world? Well, the crucial link will I take it be that of reference. It is through relations of reference holding between names and objects that a proposition "touches reality" (TLP \$2.1515), and so represents that something is the case (TLP \$4.0311). And it is therefore in these connections, the realist's view will need to be, that language is held in conformity with the world. Reference ensures - somehow - that a name shares a form with its referent, and this identity of form means that a name combination will represent a genuine possibility for the objects named. In what follows in this second section I shall run through various ways in which one might try to elaborate this proposal. In each case the conclusion will be drawn that no substantial account is after all forthcoming of how reference ensures an identity of form between its relata, and so that no substantial account is forthcoming of the stance against nonsense.

\subsection{Formal identity as a precondition on reference}

The Tractatus distinguishes sign from symbol: "The sign," Wittgenstein writes, "is the part of the symbol perceptible by the senses" (TLP \$3.32). It is a point of controversy how exactly this distinction should be understood. Uncontroversially, however, the sign-symbol contrast is a contrast between a mark or sound on the one hand and something intrinsically syntactic on the other.

Now under a common way of thinking about Tractarian symbols, a symbol's form or syntactic nature is generated by us in our syntactic use of its sign, by the rules we set down for using its sign in well formed sentences. And this use, the thought continues, is constitutively independent of any matter of 'the world'. Syntax is constitutionally separate from semantics. From here, an obvious placement for the name-object identity of form is as a precondition on reference. A symbol's form is generated by us in our syntactic use of its sign. Subsequently, symbols so generated may be given semantic content; in particular, simple symbols or names may be assigned objects as their meanings. So as Hacker writes:

Logical syntax is a matter of the rules of language. Giving content to the forms thus created is not. (Hacker 1997 p73)

But however content is then assigned, the assignment is not unconstrained. Rather, we can assign an object to a name as its meaning only if the object's form matches that of the name. But why, we need to ask, should reference be so constrained?

Casting around, the only visible option for answering this question would be to bring into play a particular understanding of Wittgenstein’s context principle (TLP \$3.3). So Hacker, again, writes:

Names have a meaning only in the context of a proposition... One projects a state of affairs into a representing fact, and the elements of the representing fact stand for the elements of the state of affairs represented. The method of projection is 'to think the sense of the proposition' (TLP $3.11) \ldots$ The sense of a proposition is (roughly) the (possible) state of affairs it represents, and 
thinking the sense of a proposition is, I suggest, intending or meaning BY the proposition (the sentence in use) that state of affairs. In so doing, one means by the constituent names of the proposition the constituent objects of the state of affairs meant. So it is the speaker's meaning (meinen) that correlates names with objects that are their meanings (Bedeutungen). (Hacker 2010 p279)

The correlation of an object with a name is essentially an element within an episode of providing a proposition with a sense that is a possible state of affairs. And this, one might perhaps hope, can explain why reference entails an identity of form: if there were no such entailment, then reference would threaten, at least, to be possible outside the context of the representation of a possibility. But here we have run around in a circle. Our ambition was to explain the stance against nonsense with an account of how reference entails an identity of form. But this identity of form is now being explained by a claim that what a proposition represents is a possibility - a claim that there is no such thing as representing a nonsense. Little wonder, perhaps, that Hacker speaks of an unargued assumption.

\subsection{Syntax as deriving from the referent}

The above circularity arose from a context in which a symbol's having the same form as an object is a precondition for its referring to that object. Looking then to reject that context, a natural alternative is that the symbol's form derives from that of its referent. Rather than supposing that we first cut names, as it were, and then subsequently correlate objects, one might propose that we cut the name to the shape of the already correlated object. A name's form is generated by us in our syntactic use of its sign, and this matches the form of the object referred to for we use the sign precisely so as to generate such a match.

This proposal may seem a more promising first move towards an explanation of how reference implies an identity of form. Immediately, though, it comes under an obvious pressure. For the suggestion that we use the sign in the way we do because of the nature of the object looks like a claim that, given the nature of the (would-be) referent, a certain syntactic use is appropriate for the sign, and we put it to that use because this is the correct thing to do. But Wittgenstein's position is that the formal match isn't merely correct but necessary; nonsense is ruled out not as something somehow incorrect but as something somehow impossible. The position to be affirmed, then, is that a name's referent compels a certain syntactic use rather than merely rendering that use correct. And so indeed Norman Malcolm, for example, writes:

Although a name and its object have the same 'form', the 'form' of the name (its logical syntax) is dictated by the form of the object. (Malcolm 1986 p30)

When I construct an elementary proposition in order to analyse some state of affairs, I correlate names with objects. For any given object I know its possible combinations with other objects. When I correlate a name with an object it is thereby settled for me in what linguistic contexts that name can occur. The name has a definite grammar: but it has that grammar only because it is correlated with a specific object. (Malcolm 1986 p31)

And David Pears:

When a name is attached to a thing, the nature of the thing takes over and dictates its subsequent use. (Pears 1987 p65) 
The thing, with its independent nature, is the dominant partner in the [object-name] association, and if the name does not remain faithful to the possibilities inherent in the thing, the association is annulled. (Pears 1987 p75)

But how is the dictating to work? How does the object's form make a certain syntax compulsory rather than merely correct?

Pears and Malcolm offer differently shaped stories here. Malcolm's apparent position is that the relation of reference between name (or name-sign) and object is effected by a mental act on the part of the subject - as Malcolm puts it, 'I correlate' the name and the object - and that this act then forces a certain syntactic use on the part of the subject, it settles for the subject in what linguistic contexts the name can occur. But I take there to be little hope for such a position, at least as Malcolm intends it. The idea cannot be that, having made the correlation, it is psychologically impossible for the subject to use the name in certain contexts, for Wittgenstein's stance against nonsense is not a psychological matter. The only prospect for hardening the 'must' here, however, is to make it somehow a part of the subject's correlation, rather than a necessary consequence of it, that the sign is used so as to match the object. And Malcolm does not, apparently, envisage any such view. Certainly he provides nothing by which it might be elaborated.

Pears' slightly different position is that the initial attachment of an object to a name does not entail a certain syntax: it is possible for the attachment to be made but then for the name to be used in a manner not matching the form of the object. In such a case, however, the association will be annulled and there will not be reference to the initially attached object. Why? Well, as with Malcolm, the explanation will have to flow from the internal character of the relation of reference, and this means that reference will now be constituted of two things, of both an initial attachment and a derived syntactic use. But again this position is unpromising. It is all very well to insist that reference is partially constituted by the name sign's having a matching use, so that in the absence of that use we necessarily do not have reference. But without an account of how the other element, the initial attachment, interacts with this second part to generate a distinctive relation of 'standing for', the insistence will be merely terminological: one will merely have decided not to call the attachment reference unless it is accompanied by the right use. And here we run into a wall, both philosophical and exegetical. There is nothing in the Tractatus elaborating what Pears' attachment might be such that, where accompanied by a derived, matching use, we have a distinctive relation of reference not present without that use. There is, that is to say, nothing in Wittgenstein's book - or indeed anything ready outside that book - with which to understand Pears' position.

\subsection{An improved derivation idea}

The 'derivation' pictures found in Pears and Malcolm appear then to fail. But perhaps we can follow leads from our discussion to arrive at a better such picture. A thought we had with both Pears and Malcolm was that reference can entail - with the necessary strength - an identity of form between its relata only if that identity is a part of what it is for the relation to hold. And with Pears it seemed that the notion of part here cannot be that of a separable component. If this is right, then the realist's way forward, one might think, must be to reject the assumption under which we have so far been operating that a symbol's syntax is generated in constitutional independence of 'the world'. Where we have so far thought of syntax as something generated in our practices, whether those practices are either prior to (Hacker) or dictated by (Pears, Malcolm) the forms of objects, the view must rather be that a name's intrinsic form is constituted within the relation of reference - and indeed is constituted there precisely so as to match the form of the referent. A name's syntax doesn't derive in some external way from the form of the object; rather, the name's intrinsic form is constituted as a reflection of the nature of its referent. 
It will be a part of any such view that a name includes the relation of reference, and so includes its referent. How could this be? Well, a first move will be to insist quite rightly that it is symbols and not signs that are the meaning bearers. In particular, names - what refer - are not signs but symbols. (It's not obvious how well Pears and Malcolm accommodate this point.) How though are we to understand a symbol such that it includes the relation of reference? Well, the obvious thought to have here may be illustrated by comparison with the game of chess. The pieces of a game of chess played as usual with blocks of wood on a board have certain powers of movement. This piece can move diagonally, say, but not forwards and back. And by way of clarifying this claim, one might plausibly press that what has such powers of movement are not the mere blocks of wood but rather the blocks of wood as they are in use in the game with just those powers. What can move in this way but not that is not the mere piece of wood but Jack's bishop. Now whether or not one agrees with that understanding of chess, the suggestion provides a partial model for one way of thinking of reference. What refers, one may propose, is not the sound or mark, the Tractarian sign, but the sound or mark as it is in use in referring: the Tractarian symbol. In this way, what refers includes the relation of reference.

We need more, however, than that what refers includes its referent. We need what refers to include its referent in such a way that its intrinsic syntactic nature is constituted as a reflection of the object's independent ontological nature. And for this we shall need to move on from any chess comparison. The view to be pursued is not, however, hard to see. What one wants is not only that what has a syntactic nature, the symbol, is the sign in use as referring, but further that it is a part of what it is to use a sign to refer that one use it with a syntax matching the form of the referent.

To be able to say what is wanted is not, however, the same thing as being in position significantly to maintain the view. How, it remains to be seen, is the proposal to be provided with enough substance that it becomes a genuine option? The challenge here parallels that facing the earlier realist accounts. What, we can ask, is it to use a sign to refer such that this necessarily involves using it with the form of the referent? Why should it be ruled out that to use a sign to refer might sometimes involve using it with the form of the referent, but at other times involve using it with a different form? And as with previous accounts, it is very hard to see what the realist might say in response to this challenge. (One might perhaps try, as a first move, an idea that reference is essentially an element of the expression of a possibility. But as before with the 'precondition' view, this takes us in an immediate circle.) To repeat: the basic proposal that a name's syntax is constituted as a reflection of the nature of its referent can readily enough be sketched as an idea that what refers is a sign in use as referring, and that to use a sign to refer is to use it with a syntax matching the form of the referent. This proposal will appear to be an advance on more traditional derivation accounts, for it makes the harmony between language and reality an inseparable aspect of the relation of reference, as opposed to separable part of that relation or worse still a constitutively distinct consequence of that relation. It remains thoroughly unclear, however, how the realist might expand the idea so as to provide a genuine understanding of that harmony.

\section{Facts as sayables and propositions as sayings}

\subsection{Introduction}

I have suggested that realist interpretations of the Tractatus are constrained when it comes to understanding the harmony between language and reality to seeing reference as doing the heavy lifting. Language must conform with the language-independent reality, and since the relation connecting language with that reality is reference, the claim will need to be that it is through reference that the conformity is enforced. The ensuing 
complaint has then been that no matter how the realist conceives either of referring names or of the nature of reference, it is very hard to see how the relation can carry the required weight, how it can be substantially understood such that it entails an identity of form between its relata. I take this to be an adequate reason to move on from the background realism with its commitment to an idea of syntax as conforming to a theoretically independent world.

Where else can we go? Well, to reject that reality is theoretically independent of language is, amongst other things, to reject that facts are to be understood independently of matters of representation, that it is incidental to the basic nature of a fact that it can be represented. And so a non-realist starting point will be that facts are from the beginning the kinds of things to be represented. The notion of a fact is that of a representable. In what follows I shall develop two stories from this basis, both developments of a common core. The first of these stories doesn't merely understand facts only in connection to representation, and so to propositions: it furthermore prioritizes propositions over facts, seeing propositions as comprehensible separately from any non-linguistic matter of 'the world'. In its prioritizing of language over reality, this story can reasonably be called idealist. Having raised a concern related to its idealism, a second story will then be outlined, a story which, whilst it again understands facts only in connection to propositions, equally understands propositions only in connection to facts. Such a story will be neither realist nor idealist. Let's begin, however, by setting out not the differences between these two stories but their common, non-realist core.

\subsection{The common core}

A proposition, Wittgenstein writes, says something (TLP $\$ 4.022$ etc.). The first aspect of the non-realist core will be to insist that this is no kind of thesis; rather, it is an elaboration of what Wittgenstein means by proposition. A proposition, for Wittgenstein, is not understood other than as a 'saying sentence'. Second, the non-realist will make a comparable assertion regarding facts. Wittgenstein holds that a fact can be said (TLP $\int \$ 3.001,3.144$ etc.), but again this is no kind of thesis; rather, it is an elaboration of what is meant by fact. A fact, for Wittgenstein, is not understood other than as something to be said, other than as a sayable. Third, and finally, the non-realist will want to harden these two thoughts up. Propositions are composed of elementary propositions and these are composed (in a different sense) of simple symbols or names. When it is held, however, that propositions are essentially sayings, this is to be understood austerely as a claim that a proposition has no substance separate from the notion of saying. And so it is to imply that names are to be understood only in relation to saying, and so only in relation to propositions. If a name had substance independent of the notion of saying, then a proposition would equally possess such substance. But a proposition possesses no such substance, and so what a name is, essentially and exhaustively, is a possible part of propositions. Similarly, we then repeat, facts are composed of atomic facts, and these are composed (in a different sense) of objects. But when it is held that facts are essentially sayables, this is to be taken as an austere position that facts involve no saying-independent substance. And so it is to be taken as implying that what an object essentially is, is a possible part of facts (TLP \$\$2.012-2.0123).

As I shall understand it, these 'austere' identifications of propositions as sayings and facts as sayables represent the entire 'non-realist core': everything else belonging to that core is simply an unpacking of these identifications. But everything else is really quite a lot. I can't here fully develop the consequences, but we can usefully sketch how to gather an understanding of Wittgenstein's picture theory, of his stance against nonsense, and of the name-referent identity of form.

Propositions, we've said, are precisely sayings. And this means that propositional structure means structure through which the proposition says something. To say that the proposition divides in a certain way is to say that it is in this division that the proposition says what it does. This point, significant enough 
already, can then be extended to a claim that propositional structure means structure not only in the act of saying but in the fact said. A fact is precisely a sayable. And this means that no significant distinction or comparison is possible between the saying structure of the proposition, the structure through which the proposition says what it does, and the structure of the fact it says. If saying a fact were a matter of latching on in a certain way to something given separately from the possibility of so latching on, then a contrast would indeed be possible between the structure of the act of latching, as it were, and the structure of its object. With a fact understood as a sayable, however, no such comparison is possible. To repeat: if, given the saying of a fact, one doesn't take the saying's structure to provide in itself that of the fact said, if one takes it to be a further question, given the structure of the saying, how the fact is structured, then one is taking the fact to have structure independent of the notion of saying, and so to have substance other than as a sayable.

This relatively simple thought provides, I think, the essentials of the picture theory. First it gives an idea of reference. A structural correlation between proposition and fact is at once a correlation between their elements: to correlate the structures is to correlate their elements. A proposition's components can therefore be said to mean the components of the sayable it says, to have its components as their meanings:

The name means the object. The object is its meaning. (TLP \$3.203)

And more than this, our idea that a proposition's structure is structure in the fact said is I think precisely Wittgenstein's claim that what an elementary proposition represents is that the objects meant by its component names are so combined, combined as their names are combined in the proposition:

That the elements of the picture are combined with one another in a definite way, represents that the things are so combined with one another. (TLP \$2.15)

Rather than dwell on the picture theory, however, let's return to this essay's leading concerns, beginning with the identification of representability and possibility.

The representability of what is possible is straightforward. Objects, we have said, are essentially possible elements of sayables. And given our proposition-fact structural identity this means that they are essentially possible meanings of a saying's components, essentially possible name meanings. There can therefore be no unrepresentable possibility, for there is no notion of name meanings combining in a manner impossible for names with those meanings. As, conversely, for the possibility of what can be represented, this might seem to fall immediately out of the understanding of facts - possible object combinations - as sayables. It is not quite so immediate, however, for whilst this identification straightforwardly entails the possibility of what is said, it is not immediately ruled out that there should be representations that are not sayings. A possibility is indeed precisely a sayable, but perhaps meaningful names can combine in a manner not of a saying sentence, thereby constituting a representation that certain sayable elements combine in a manner not of a sayable, a representation of an impossibility. Standing against this, however, is the priority of propositions over their parts. What a name essentially is, is a possible part of propositions - that is, of sayings. There can therefore be no 'illegitimate sentence' representing an unsayable, for there are names only within the context of a saying. There is no representation other than saying, then, and what is representable is also possible.

It is worth pausing at this point to note something this essay lost sight of in the discussion of realist positions, namely Wittgenstein's claim that a proposition contains the possibility of the fact it represents. For the earlier realist positions, at least, it wasn't clear that even if nonsense were ruled out one would have a story 
under which this claim could happily be made. On the current view, by contrast, the form of a representation contains the form of the fact it represents - and it contains it as such, as the form of a possibility.

Turning finally to the name-referent identity of form, this is much less prominent in the Tractatus than the stance against nonsense, and on the current account it is indeed buried deeper in. We have that propositional structure is structure in the represented fact. To get from here to an idea that there is a match in kind also between the elements of the structures, we shall need to see that the structure of the proposition or fact just is, in a certain sense, the formal nature of its parts. More specifically, the key thought will be that a propositional or fact mode of combination has no internal character beyond that of being a mode of the unique name or object types which may so combine. If entities (or names) of forms $f$ and $g$ can combine in mode $M$, then there is nothing to mode $M$ beyond its being a mode in which forms $f$ and $g$ may combine. Or to put the matter in terms of roles rather than modes, the role an entity of form $f$ plays in an $f-g$ combination has no internal characterization other than as that of combining, as an entity of form $f$, with an entity of form g. To see this, suppose the contrary, namely that Tractarian combinatorial roles may be given independently of the unique entity types able to play them. Then it follows that the entity types would equally be given independently of the combinatorial roles they may play. Why? Well, because without such an independent understanding of the types, no sense could be made of an entity, with a nature, playing a combinatorial role. To suppose that some thing is playing such a role is to suppose that something of a certain kind is playing that role, and so if having the role in view does not mean having in view also a unique entity kind, then the entity's kind must arrive from elsewhere, from the entity itself in separation from the role it is there playing. But this is something Wittgenstein is set against: a Tractarian entity has no nature other than that of a role player in facts.

A propositional or fact mode, we thus repeat, has its content as a mode of the unique name or object types which may so combine. Combining this with the Tractarian commitment seen above that a proposition's mode internally provides that of the fact it says, we may infer a formal identity between a name and its meaning. In a proposition, the name types are sufficient for the propositional mode. The propositional mode then internally gives that of the fact said. And the fact mode then determines in itself the unique object types which may so combine. Putting these together we then have that the name types internally fix those of their meanings.

\section{3 'Our language game of propositions'}

The 'non-realist core' could no doubt use a more thorough and lucid development. It is immediately apparent, however, that the stance against nonsense in no way leans on a prior thesis of a name-referent identity of form. Rather, these two Tractarian positions both fall out of Wittgenstein's identifications of propositions as sayings and of facts as sayables. Insofar, then, as we want a fuller understanding of the stance against nonsense, and assuming it was clear enough above how the falling out will run, what we shall need to do is to place these two identifications together in a broader theoretical context. How, as it were, are we supposed to work with them? In what follows I want to consider two rather different options for answering this question.

The first option may sound somewhat late Wittgensteinian, understanding the core with appeal to a notion of 'our language game of propositions'. We play, the idea would be, a language game of propositions. And Wittgenstein's Tractarian philosophy of language is a theoretical account of this game. In particular, Wittgenstein's austere identification of propositions as sayables is to be understood as a claim that this game's central move is one of saying something, with other key notions of the account, in particular those of name and reference, to be understood only in relation to this central idea. Saying something is the unit move, as it were, in the language game. 
Providing substance for our purposes to this talk of language games will then be an idea that moves within the game of saying something have their identity only as such, as moves in the game. Much as checking one's opponent or capturing a bishop are essentially moves in the practice of chess, so, the thought will be, sayings are to be understood only as moves within the language game of saying. This thought has the important consequence that the Tractarian ontology of sayables and their constituents will need to be seen as deriving from matters internal to the game, that ontology derives from language. Why? Well for the simple reason that if there were non-linguistic substance to sayables, then such substance would belong also to sayings which include what they say - but this is what is being ruled out. One will need, then, an account of how ontology derives from language. And here an idea might be that the Tractarian account of our practice of saying includes the possibility of identifying two names as having the same meaning, or two propositions as saying the same thing, and that talk of objects and facts is simply a reflection of these possibilities. Talk of a certain object will be talk of a certain meaning, internal to the language game, which may be had by different symbols. Talk of a certain fact and its obtaining will be talk of a certain saying type and its truth. The priority of fact over object will thus be in effect a mere restatement of the priority of proposition over name, of saying over naming. (Here one might make an association between meaning and use, drawing on such comments as TLP \$3.326: "In order to recognize the symbol in the sign we must consider the significant use", and TLP \$3.328: "If everything in the symbolism works as though a sign had meaning, then it has meaning".) And so Winch talks of "the misunderstanding of supposing that a name's meaning is something other than and prior to its logico-syntactic role" (Winch 1987 p10).) I don't want, however, to examine any particular story of how, as Ricketts has put it, "ontological notions are supervenient on logical ones" (Ricketts 1985 p6). Indeed, I don't want to saddle any particular author with the wider account being sketched. Rather, I want only to raise a concern for that account.

In an obvious sense, the current line is not merely non-realist but idealist. Ontology, it is suggested, is to be understood only through language (the non-realist core), which is in turn to be understood without reference to anything non-linguistic (sayings are essentially and exhaustively moves in the language game). And this is liable to cause concern, I think, when held, as it is, in tandem with the idea of language as a practice. The description of this concern will be somewhat sketchy, but let's begin with the thought that practices are things of our making. We practitioners determine by our social behavior, by the rules or conventions or institutions that we lay down, acknowledge, and operate within, what our practice is. To think of 'our language game of saying' as a practice is thus to think of the act of saying - something whose identity is fixed only within the practice - as something whose nature is of our making. If it is added to this that ontology is without substance separate from saying, however, then ontology too be of our making. Insofar as saying is a matter of our social behavior, then so too is ontology. And at this point one may well want to get off the boat.

The idealist might respond to this complaint by rejecting that practices are in the suggested sense 'things of our making'. Our social behaviour does indeed determine what our practice is, but only in the sense of determining which practice is ours: the practice is in itself something separate from our behaviour. To repeat: practices are 'out there to be played', and the behaviour of a group does not determine the nature of such a practice but rather selects that it is this and not that practice that they are engaged in. But whilst this may be a reasonable way to think in some contexts, the proposal would appear absurd when we add, again, that ontology is to be a projection from practice. The response on offer here depends upon an idea of a range of possible practices, with our group behaviour serving to select between them. And to think of our behaviour as selecting between practices is to think of our having the practice we do as a contingency - which would make it a contingency that we have the reality we do. Had we followed different social rules, we would 
have lived in a different world. But that makes no sense, for it means: had in this world we followed different social rules we would have lived in a different world.

Alternatively, then, and more likely, the response may be made that the sense of a problem here depends upon false assumptions of contingency. Why is it unpalatable that ontology be grounded in our practice? Well, because it makes no sense to think of ontology as grounded in the contingent practice of a contingent community. But it is no contingency, the response is possible, that we adopt the rules of saying rather than the rules of some other practice. Saying is not in this way like chess. Rather, our participation in the practice of propositions defines our essential identity as thinking, rational beings. The idea that we might instead have played some other game does not therefore take a grip. And as for the idea that we form a contingent community, this too is mistaken. The world's nature - the forms of object, say - cannot indeed be seen as a reflection of the practice of a contingent community in the world, the community of rational beings. But what this shows is that the 'we' of 'our practice' has no third personal specification. It does not serve to pick out a group which might otherwise be picked out third personally.

Again, though, the defence seems problematic. As a condition of asserting "The world is my world", the solipsist will need to reject "I am NN" where "NN" names a person, an element of the world. Similarly, it seems, the current view is committed to "The world is our world", and as a consequence will need to reject "We are these" where "these" names a community of thinkers. In both cases, the position may not seem happy. More pointedly, though, it can seem less happy in the current case than it does for the solipsist. For the solipsist's arrival at "The world is my world" will presumably not involve the self-ascription of "worldly properties'. One will not come to say "The world is my world" through having a thought "I am F" where "F" names property whose possession would tend to locate one in the world. The going history of "The world is our world", by contrast, includes a thought "We take part in a practice of saying" - something which would seem to situate the 'we' squarely within the world as contingent agents.

These concerns with the idealist, language game proposal are quick, of course, as indeed was the characterization of the position they target. We are touching here on large issues which I cannot begin properly to pursue. It should hopefully be clear enough, however, that the proposal faces difficulties arising out of its introduction of the first person. And I want to take this both as a reason to move on, and also as an indication of how to move on. What we must do is remove the 'we' and with it the idea, late Wittgensteinian or otherwise, of a practice: the act of saying in which we are interested does not have its identity within some social custom. Of course, in making this move we lose the 'broader context' on offer for our non-realist core. And so we shall need another.

\subsection{Sayings, sayables and truth}

What is wanted here may not be entirely clear; it may not be clear what will and will not count as an adequate elaboration or situating of the core. In any case, I shall not bring to bear any new theoretical idea replacing that of a language game. Rather, I want only to understand the core in relation to the notion, already implicitly present within it, of truth.

First, though, we can offer an outline in terms familiar from above. A sayable, the proposal will be, whilst not something extra-linguistic in the sense of something whose nature carries no reference to language, is nonetheless something non-linguistic. A sayable is a way for things to be, a fact or possibility, and whilst a way for things to be is in its nature something one can say, it is not on the going view to be thought of as something linguistic, something deriving from language. (The non-realism of the core is not in itself an idealism: that was an addition of the last story.) Conversely, and this is perhaps the more non-standard element, a saying or proposition, whilst obviously something linguistic, is nonetheless not something 'purely linguistic', something constitutionally separate in its form from the non-linguistic world. Rather, a 
proposition intrinsically involves the form of the non-linguistic fact it expresses: its own form is intrinsically that of a saying of a sayable of the kind said. We crossed an idea roughly similar to this above with the final attempt at a realist position, the suggestion that a name's form is constituted as a reflection of that of its object. For the most part, though, the assumption has been of linguistic form as, in one way or another, generated in constitutional independence of anything non-linguistic. But this is now being rejected.

One way to approach the current (and final) view, then, is to note that from the position of a standard realist account, it recommends at once a 'softening' of the world and a 'hardening' of language. Standard realist accounts see linguistic form as generated in independence of matters non-linguistic, and the non-linguistic world as 'out there' independently of any matter of language. An alternative realist account, the last we considered, wants instead to 'harden up language' and see linguistic form as deriving constitutively from that of the world. And that is a move in something like the right direction. Equally, though, we can advance from the standard realist by keeping the autonomy of language but rejecting that of the world, arriving at an idealism. The current thought, however, is that the proper stance combines moves of both kinds and rejects autonomy on both sides of the representational affair. Neither language nor the world is to be understood separately from the other.

To colour this outline in we then draw, as advertised, on the notion of truth. Truth, the basic thought will run, is what holds the two sides together: neither language nor reality is to be understood separately from the notion of truth, and with that neither may be understood separately from the other. Spelling this out slightly, we shall first identify facts as truth conditions. A fact is in its conception something upon whose obtaining the truth of a proposition depends, and so it is in its conception something to be represented by a proposition. A fact is a truth condition, where this means the truth condition of a possible representation, and so a representable. Turning to propositions, these will be understood as, precisely, representations of truth conditions. Indeed, given the aspect of our core that a saying and what it says match in their internal structure, we can speak of propositions as expressions of truth conditions (TLP \$4.432). And so we have the following: a Tractarian fact is precisely a truth condition, where this means truth condition of a possible expressing, and a Tractarian proposition is precisely the expressing of such a fact, the expression of a truth condition.

The Tractatus understands both the forms of language and the forms of reality as equally the forms of truth. On both sides, the form is logical. Crucially, moreover, the pride of place Wittgenstein assigns to the notion of truth does not mean merely that truth permeates both sides of the representational affair: its force is rather that no substance attaches to either side separately from that notion. An object isn't merely something which can by its nature participate in truth conditions: its nature is precisely the possibilities it has for such participation. A name is not merely something which can by its nature participate in the expression of truth conditions: its nature is precisely its possibilities for such participation. And it is this austere basic vision of Wittgenstein's book, the proposal will run, and not some idea that saying is the unit move in our language game, that provides the proper context for understanding our 'non-realist core', and so for understanding together all three of the picture theory, the identification of representability and possibility, and the name-object identity of form.

Colin Johnston, University of Stirling

\section{Acknowledgments}

This work was supported by the Arts and Humanities Research Council, grant number AH/J004286/1. 


\section{References}

Hacker, P. (1997). Insight and illusion. Bristol, Thoemmes Press

Hacker, P. (1999). 'Naming, thinking and meaning in the Tractatus', Philosophical Investigations 22(2): 119-135

Hacker, P. (2010). 'The development of Wittgenstein's philosophy of psychology' in P. Hacker and J. Cottingham eds. Mind, Method and Morality Essays in Honour of Anthony Kenny. Oxford, Clarendon Press: 275305

Malcolm, N. (1986). 'Language and the objects' in Wittgenstein: nothing is hidden. Oxford, Blackwell

Pears, D. (1987). The false prison vol. 1. Oxford, Clarendon Press

Ricketts, T. (1985). 'Frege, The Tractatus, and the Logocentric Predicament', Nous 19(1): 3-15

Winch, P.1987: 'Language, Thought and World in Wittgenstein's Tractatus' in Trying to Make Sense. Oxford, Blackwell

Wittgenstein, L. (1922) (TLP). Tractatus Logico-Philosophicus. Tr. C. Ogden. London, Routledge 